\title{
3 Research Square

\section{MiR-142-3p could serve as a potential biomarker for individualized treatment of solitary and multiple leiomyomas}

\section{Luqi Xue}

Sichuan University West China Second University Hospital

\section{E Yang}

Sichuan University West China Second University Hospital

\section{Zhengyu Li ( $\nabla$ zhengyuli@scu.edu.cn )}

Sichuan University West China Second University Hospital

\section{Jinhai Gou}

Sichuan University West China Second University Hospital

\section{Dan Nie}

Southwest Medical University

Jia Jia

Qinghai Red Cross Hospital

Juntao Feng

Guangxi Medical University First Affiliated Hospital

\section{Tao Yi}

Sichuan University West China Second University Hospital

\section{Research article}

Keywords: solitary leiomyoma, multiple leiomyoma, MiR-142-3p, Wnt signaling pathway

Posted Date: April 14th, 2020

DOI: https://doi.org/10.21203/rs.2.22979/v2

License: (c) (1) This work is licensed under a Creative Commons Attribution 4.0 International License. Read Full License 


\section{Abstract}

Background The pathogenesis and clinical behaviors between solitary leiomyoma (SL) and multiple leiomyomas (ML) vary, which lead to the difference in management for childbearing-aged patients. Herein, we aim to find the potential miRNA biomarkers for optimizing the individualized management between SL and ML.

Methods A microarray analysis was conducted to screen out the potentially dysregulated miRNAs. Target genes and signaling pathway potentially involved in UL pathogenesis were predicted by bioinformatics. The effect of miRNA was examined by Cell Counting Kit-8 proliferation assay and qRT-PCR after transfection of miRNA mimics

Results The top 5 differentially expressed miRNAs, Wnt signalling pathway and its two central molecules APC and CTNNB1 were screened out according to microarray analysis and bioinformatics. MiR-142-3p was selected for further exploration. In validation of qRT-PCR, MiR-142-3p was significantly upregulated in SL, while downregulated in ML, CTNNB1 and sequencing target AXIN-2 were expressed at higher level in ML than SL. Overexpression of MiR-142-3p resulted in lower transcription level of CTNNB1 and AXIN-2, and lower cell proliferation level.

Conclusions MiR-142-3p may be involved in the development of SL and ML by interacting with CTNNB1 and AXIN-2 through Wnt signaling pathway. MiR-142-3p could serve as a potential biomarker for individualized treatment between $S L$ and $M L$ in the future.

\section{Background}

Uterine leiomyoma (UL) is the most prevalent neoplasm in reproductive-age females. UL is associated with menstrual bleeding, followed by anaemia, impaired fertility, recurrent pregnancy loss and complications, and accounts for the most common cause of hysterectomy among gynaecological disorders, costing an estimated \$34.4 billion in the United States [1]. However, the understanding of UL pathobiology is still in its infancy, thus alternative treatment options (other than surgical interventions) are limited. As hysterectomy is invasive and can result in permanent infertility, myomectomy has become one of the only options to preserve fertility. Several studies have reported that recurrence of multiple leiomyomas (ML) occurs at higher rates than solitary leiomyoma (SL) [2-13]. However, a significant difference was not found in some studies[14, 15], and one study reported contradicting results [16]. Moreover, clinical observation and epidemiology showed that SL tended to grow in a larger diameter and rarely developed into multiple tumours. Cytogenetic studies have suggested recurrent and mutually exclusive mutations exist in UL [17], including the most frequently mutated gene mediator subcomplex 12 (MED12)[18] and a frequently rearranged allele of HMGA2 [19]. Moreover, gene polymorphisms studies showed that carriage of higher CYP17A1 G allele frequency was correlated with ML, while higher CYP17A1 A allele frequency was correlated with a healthy population and SL [20, 21]. Taken together, these clinical epidemiology and cytogenetic studies suggested the involvement of molecularly distinct 
pathobiology between SL and ML, encouraging further study to reveal the differentiated molecular processes between SL and ML for novel perspective of UL pathobiology.

MiRNAs are negative regulators of gene expression through post-transcriptional gene silencing [22] and they have been found to take part in disease pathogenesis and embryonic development. Few studies have described miRNA dysregulation between UL versus corresponding myometrium, based on microarray analysis [23-25], which yielded some dysregulated miRNAs (miR-let7 family, miR-21, miR-34a, etc.). However, the roles of dysregulated miRNAs in UL pathogenesis is still to be elucidated. Here, aiming to explore individualised therapeutic applications and molecular interventions for UL, we investigated miRNA-target networks between SL and ML compared to their corresponding myometrium. Taken together with previous studies, we found that $\beta$-catenin signalling was significantly differentially regulated between $S L$ and $\mathrm{ML}$, as compared to their corresponding myometrium, as a potential result of post-transcriptional negative regulation by miR-142-3p directly targeting $\beta$-catenin.

\section{Methods}

Study samples: Tissues of uterine leiomyomas and corresponding normal myometrium were collected from 32 women with symptomatic leiomyomas, who underwent operations at West China Second University Hospital (Chengdu, P.R. China), and were stored in liquid nitrogen immediately after surgeries. Written informed consents were obtained from all patients, and the Institutional Review Board of West China Second University Hospital approved the study protocol. During tissue collection, eligible subjects and tissue specimens were defined as: 1) no $\mathrm{GnRH}$-a or oral contraception used before surgery; 2 ) pathological diagnosis of leiomyoma; 3 ) no accompanying adenomyosis or endometriosis; 4) minimum number of leiomyomas involved in multiple leiomyomas was 5; and 5) leiomyomas intraoperatively revealed as multiple leiomyomas fused as one were excluded from solitary leiomyoma group. 6) SL was defined as one leiomyomas identified by both ultrasound and surgery findings. And the diameter of SL should be larger than $8 \mathrm{~cm}$.

MiRNA microarray analysis: MiRNA microarray analysis was performed on three pairs of solitary leiomyoma and corresponding myometrium, and three pairs of multiple leiomyomas and corresponding myometrium. The frozen tissues were cryopulverised to fine powder with the BioPulverizer (BioSpe, America). The powdered tissue was homogenised with TRIzol Reagent (Invitrogen) using the Mini-beater16 (BioSpec), and total RNA was purified using the RNeasy Mini Kit (Qiagen). The quality of the total RNA was verified by spectrophotometry using NanoDropND-1000 (ND-1000, Nanodrop Technologies). The integrity of RNA was evaluated by denaturing agarose gel electrophoresis. RNA labelling and array hybridisation was performed according to the manufacturer's protocol (Exiqon). Total RNA $(1 \mu \mathrm{g})$ was labelled with Hy5 fluorescent and Hy3 fluorescent probes using the miRCURY Array Power Labeling kit (Exiqon). The miRCURY LNA Array version 7th generation (Exiqon) was used to hybridise the labelled RNA. Subsequently, the hybridised slides were scanned using the Axon GenePix 4000B microarray scanner (Axon), and image reading was performed using GenePix pro V6.0 (Axon). 
Microarray analysis: With a cut-off fold-change (FC) value of 2, miRNAs expression profiles of each SL and $\mathrm{ML}$ compared to the corresponding myometrium of solitary leiomyomas (MSL) and myometrium of multiple leiomyomas (MML), respectively, were yielded. Dysregulated miRNAs of three pairs of SL vs. $M S L$ and three pairs of ML vs. MML were filtered by taking intersection within groups. We further took intersections between up-regulated miRNAs in SL vs. MSL and up-regulated miRNAs in at least two pairs of ML vs. MML. The yielded miRNAs were considered not differentially expressed and excluded. Similarly, $S L$ vs. $M S L$ down-regulated, $M L$ vs. MML up-regulated, and $M L$ vs. MML down-regulated miRNAs were filtered by the same strategy. The remaining miRNAs were considered to be potentially dysregulated between SL vs. MSL and ML vs. MML. The validated functional information of each miRNA was conducted using miRTarBase 6.0 (updated to September 2015). To collect validated functional information published after September 2015, we further carried out a comprehensive online search of published studies in PubMed (US National Library of Medicine, National Institute of Health; http://www.ncbi.nlm.nih.gov/pubmed/). Publications were identified with the use of the following search strategies: microRNA [Title/Abstract]. For the same searching purpose, gene targets of validated differentially expressed miRNAs in this study were identified using the same search methodology in PubMed. Candidate miRNAs were rated in four aspects: 1) The false discovery rate (FDR): 3 points for FDR $<0.05,2$ for $0.05<$ FDR $<0.1$, and 1 for FDR $>0.1 ; 2$ ) expression condition in another group: 3 points for contrarily regulated in 2 pairs of leiomyoma vs. myometrium in another group, 2 for contrarily regulated in 1 pair of leiomyoma vs. myometrium in another group, 1 for not found dysregulated in another group, and - 2 for regulated in same way in 1 pair of leiomyoma vs. myometrium in another group; 3) expression level (normalised signal intensity (NSI)): 3 points for $\mathrm{NSI}>5,2$ for $5>\mathrm{NSI}>1$ and 1 for NSI $<1$. 4. Validated function potentially related to leiomyoma genesis (Wnt signalling/fibrogenesis/TGF/hormone synthesis or metabolism[26, 27]): 3 points for 3 items, 2 for 2 items, 1 for 1 item, and 0 for no relative research.

MiRNA gene targets prediction and pathway analysis: Target gene prediction of miRNAs (miR-142-3p, miR-146b-5p, miR-146a-5p, miR-136-3p, and miR-608) was conducted using intersections of results yielded from four miRNA target prediction databases (miRWalk 2.0, miRanda, TargetScan, and RNA22). Yielded genes were uploaded to the Database for Annotation, Visualization and Integrated Discovery (DAVID) v6.8 to perform functional annotation clustering analysis. Signalling pathway enrichment was carried out based on KEGG PATHWAY and Benjamini-Hochberg modified P-value was yielded. We further searched miRTarBase 7.0 (updated September 2017) and PubMed for validated functional information of miR-142-3p.

Quantitative RT-PCR: Quantitative RT-PCR (qRT-PCR) was performed on 13 pairs of SL and MSL and 19 pairs of ML and MML to quantify miRNAs (miR-142-3p, miR-146b-5p, miR-146a-5p, miR-136-3p, and miR608). Further, 10 pairs of SL and MSL and 10 pairs of ML and MML (all included in those tissues used for miRNA quantification) were measured to quantify gene transcripts (CTNNB1, APC, and AXIN2). Total RNA was extracted from leiomyomas and myometrium tissues using the miRNeasy Mini Kit (Qiagen) according to the manufacturer's instructions. Quality of the yielded RNA was verified using a NanoDropND-1000 (ND-1000, Nanodrop Technologies), and the integrity was evaluated by agarose gel 
electrophoresis. Reverse transcription (RT) to complementary DNA (cDNA) was conducted using the miScript II RT Kit with miScript HiSpec Buffer (Qiagen) on the GeneAmp® PCR System 9700 (Applied Biosystems, USA) according to manufacturer's instructions. MiRNAs and mRNA-specific primers were used for PCR using U6 as the housekeeping primer for miRNAs detection and using ACTB for gene transcripts. The primer sequences were designed in the laboratory and synthesised by Generay Biotech (Generay, PRC) based on the miRNA sequences obtained from the miRBase database and mRNA sequences obtained from the NCBI database as follows: hsa-miR-142-3p, GSP: 5'GGGGGTGTAGTGTTTCCTA3', R: 5'CAGTGCGTGTCGTGGA3'; hsa-miR-136-3p, GSP: 5'GGGGACATCATCGTCTCAAAT3', R: 5'GTGCGTGTCGTGGAGTCG3'; hsa-miR-146b-5p, GSP: 5'GGGGTGAGAACTGAATTCCA3', R: 5'GTGCGTGTCGTGGAGTCG3'; hsa-miR-146a-5p, GSP: 5'GGGTGAGAACTGAATTCC3', R: 5'TGCGTGTCGTGGAGTC3'; hsa-miR-608, GSP: 5'AGGGGTGGTGTTGGGACAG3', R: 5'GTGCGTGTCGTGGAGTCG3'; U6, F: 5'GCTTCGGCAGCACATATACTAAAAT3', R: 5'CGCTTCACGAATTTGCGTGTCAT3'; APC, F: 5'GATGAACAAGTTTACCCAGCC3', R: 5'TCTCTATGCACATCATGTGACC3'; CTNNB1, F: 5'ACAGATCCAAGTCAACGTC 3', R: 5'AGCTGAACAAGAGTCCCA3'; AXIN2, F: 5'CTTATTGGGCGATCAAGACG 3', R: 5'TGAATCCATTGCAGGCAAAC3'; ACTB, F: 5'CCATCATGAAGTGTGACG 3', R: 5'GCCGATCCACACGGAGTA3'. Reactions were carried out in an ABI Prism 7900 HT Sequence Detection System (Applied Biosystems) using the miScript SYBR Green PCR Kit (for real-time polymerase chain reaction [qRT-PCR]; Qiagen) according to manufacturer's instructions. Each tissue was run in independent experiments in triplicate. After PCR amplification, the relative expression of miRNAs and mRNAs was calculated based on the $2^{-\Delta C t}$ methods.[28] The relative fold-change of miRNAs and mRNAs between SL vs MSL and ML and MML was calculated based on the $2^{-\Delta \Delta C t}$ methods.[29]

\section{Cell culture, transfection of miRNA mimics, signalling detection, and cell proliferation assay: Ishikawa} cells (acquired from Key Laboratory of Birth Defects and Related Diseases of Women and Children, Sichuan university, Chengdu, China) were used instead of primary uterine leiomyoma cells due to growth failure. Ishikawa cells were cultured in Dulbecco's modified Eagle's medium (DMEM, Gibco, Carlsbad, CA) mixed with $10 \%$ foetal bovine serum (FBS, Gibco) and $1 \%$ penicillin and streptomycin (Gibco). All cells were cultured in a $37^{\circ} \mathrm{C}$ incubator containing $5 \% \mathrm{CO}_{2}$. Ishikawa cells were seeded at a density of 1 $10^{6} /$ well in a 24 -well dish and cultured for $12 \mathrm{~h}$. Following, transfection of miR-142-3p mimics ( $25 \mathrm{nM}$ and $250 \mathrm{nM}$ ) and its negative control (RiboBio, Guangzhou, China) was performed using Lipofectamine 3000 (Invitrogen) according to the manufacturer's instructions. Cells were treated with $30 \mathrm{M} \mathrm{LiCl} 12 \mathrm{~h}$ after transfection and incubated for another $24 \mathrm{~h}$. Further, the transfection effects of miR-142-3p mimics and CTNNB1, APC, and AXIN-2 gene transcripts were examined by qRT-PCR. The inhibition rate of cell proliferation was measured by CCK8 (Jikai Gene, China) at 12, 24, 36, and $48 \mathrm{~h}$ after transfection according to the manufacturer's instructions. Optical density (OD) was measured by Varioskan Flash (Thermo Scientific) at a wavelength of $450 \mathrm{~nm}$.

Statistical analysis: Quantitative data of each miRNA and mRNA were recorded as mean \pm S.E.M. A twoway ANOVA with repeated measures was used for integral data analysis as experimental group was one 
factor (two groups based on number of leiomyomas) and site was a repeated measure (paired leiomyoma with corresponding myometrium). Two-tailed paired Student's t-tests were performed for RNA dysregulated level between paired leiomyomas and myometrium. Two-tailed independent Student's ttests were performed between SL and ML, MSL and MML. Detailed statistics are shown in Supplementary file 1-2. SPSS 23.0 (SPSS) was used for analyses. GraphPad Prism 6.0 (GraphPad Software, Inc) was used for figure drawing. Statistical significance was defined as $P<0.05$.

\section{Results}

\section{The top five dysregulated miRNAs between SL and ML were filtered by microarray analysis}

To determine potentially dysregulated microRNAs between $S L$ and $M L$, we firstly performed a miRNA microarray analysis of $12 \mathrm{UL}$ samples, including 3 pairs of SL with their corresponding MSL and 3 pairs of $\mathrm{ML}$ with corresponding MML. Only patients with more than 4 leiomyomas were included in the ML group, according to the meta-analysis results. Based on a cut-off fold-change (FC) value of 2 and Sanger miRBase (version 19.0, http://microrna.sanger.ac.uk/sequences), 38 miRNAs were up-regulated in SL (SL vs. MSL) and assigned into SL up-regulated group. 17 miRNAs were up-regulated in ML (ML vs. MML) and assigned into ML up-regulated group. In a similar fashion, 16 miRNAs were in SL down-regulated group and 4 miRNAs were in ML down-regulated group (Fig. 1).

Then the differentially expressed miRNAs between SL groups and ML groups were further filtered. 10 miRNAs in SL up-regulated group were excluded for they also up-regulated in at least 2 pairs of tissues in ML up-regulated group. Similarly, 3, 2, and 2 miRNAs were excluded from SL down-regulated group, ML up-regulated group and $M L$ down-regulated group, respectively (Table 1.1-1.4). The remaining 28, 15, 13 , and 1 miRNAs were considered to be potentially dysregulated miRNAs among groups and were ranked based on the following four items: false discovery rate, expression condition in another group, expression level and stability, validated function potentially related to leiomyoma genesis. Additional details can be found in Table 1.1-1.4 and Methods. As a result, the top 5 ranked miRNAs: miR-142-3p, miR-146a-5p, miR146b-5p, miR-136-3p and miR-608(Fig. 1 and Table 1.1-1.4) were filtered for further validation in enlarged UL samples.

\section{miR-142-3p was the most dysregulated miRNAs between SL and ML}

Secondly, qRT-PCR was used to validate the top five miRNAs' expression in enlarged UL samples (13 pairs of SL vs. MSL and 19 pairs of ML vs. MML, total 64 tissues) (Fig.2). Based on microarray analysis, the expressions of miR-142-3p, miR-146b-5p and miR-136-3p were significantly different between SL groups and ML groups (Fig. 2a). MiR-142-3p was significantly upregulated in SL group by $2.236 \mathrm{FC}$ value, while downregulated in ML group by -1.757 FC value. Moreover, the baseline expression of miR-142-3p in MSL was significantly lower than $M M L$, and the expression level in SL was significantly higher than $M L$ (Fig.2b). Similarly, miR-146b-5p was upregulated in SL group by 1.858 FC value, while downregulated in $M L$ group by -1.398 FC value. Varying from miR142-3p, baseline expression of miR-146b-5p in MSL and MML showed no statistical difference (Fig. 2c). MiR-146a-5p, which harbours the identical seed region 
with miR-146b-5p, was downregulated in both groups by -2.263 FC and -1.700 FC, respectively. However, no significant interaction between groups and sites was found between SL group and ML group (Fig. 2d). MiR-136-3p was significantly upregulated by 3.208 FC and 1.270 FC between SL group and ML group, respectively, due to a lower baseline expression in MSL and similar upregulated levels in SL and ML (Fig. 2e). No statistical difference was found in miR-608 (Fig. 2f). Above all, miR-142-3p was the most dysregulated one between $S L$ and ML. Although miR-146b-5p showed a similar expression profile with miR-142-3p, miR-146a-5p shared identical seed regions with miR-146b-5p and showed a different expression profile.

\section{Targets and pathway analysis of miR-142-3p.}

After microarray analysis and qRT-PCR validation, we focused on researching miR-142-3p including its target genes and pathway analysis. Target gene prediction of miR-142-3p was conducted by taking intersections of results yielded from four miRNA target prediction databases. Briefly, 343 genes were uploaded to the Database for Annotation, Visualization, and Integrated Discovery (DAVID) v6.8 to perform functional annotation clustering analysis. Based on KEGG PATHWAY (Benjamini-Hochberg modified Pvalue $=8.7 \mathrm{E}-1$ ) and a previous miR-142-3p target gene signalling prediction conducted through miRTar by Carraro et al [30], the Wnt signalling pathway was the first significantly enriched signalling pathway. Interestingly, activation of Wnt signalling was reported to resulted in myometrium cell hyperplasia and development of leiomyoma-like tumours in a Cre-recombinase mouse model [31]. We further searched miRTarBase 7.0 and PubMed for validated functional information of miR-142-3p and found that the regulation of canonical Wnt signalling by miR-142-3p was explored in several studies. However, involvement of different target genes showed contrary regulation results. Isobe et al.[32] and Carraro et al. [30] reported that miR-142-3p activated canonical Wnt signalling by targeting APC, a member of the $\beta$ catenin (CTNNB1) destruction complex. Hu et al.[33] reported that miR-142-3p inactivated the canonical Wnt signalling pathway by directly targeting CTNNB1. Further, Shrestha et al [34] reported that $\beta$-catenin protein levels increased, while the CTNNB1 gene was not altered in miR-142 knock out mice. APC and $\beta$ catenin were both validated as miR-142-3p targets by luciferase assay [30, 32, 33]. Interestingly, several studies have suggested that the intracellular $\beta$-catenin pathway of Wnt signalling is constitutively active in the majority of LM cells [31, 35]. Therefore, APC and CTNNB1, two central molecular of Wnt signalling and validated gene targets of miR-142-3p, were selected for further validation.

\section{Contrary to the expression of miR-142-3p, CTNNB1 and AXIN2 were significantly upregulated in ML}

APC and CTNNB1, potential dysregulated target genes of miR-142-3p (Fig. 3a) and central members of the canonical Wnt/ $\beta$-catenin signalling pathway, and AXIN2, a $\beta$-catenin signalling target gene, were further validated in another UL samples (10 pairs of SL and 10 pairs of ML, a total of 40 tissues included in previous miRNA validation). The results showed that CTNNB1 was upregulated in both SL group and $\mathrm{ML}$ group, but with a significantly higher FC value of 12.327 in $\mathrm{ML}$ group (Fig. 3a). Furthermore, the baseline expression of CTNNB1 between MSL and MML, and upregulated levels between SL and ML, were significantly different (Fig. 3c), consistent with the miR-142-3p expression profile. Conversely, the 
expression of APC showed no differences in any statistical comparisons (Fig. 3b, e). AXIN2, representing the activated level of $\beta$-catenin signalling, was significantly upregulated at $2.303 \mathrm{FC}$ value in ML group. The detailed expression profile was consistent with CTNNB1 (Fig. 3b, d).

\section{MiR-142-3p overexpression downregulated CTNNB1 and AXIN2 and inhibited cell proliferation in vitro}

To further investigate the function of miR-142-3p on $\beta$-catenin signalling, we detected the expression changes of the predictive target genes and subsequent downstream genes of $\beta$-catenin signalling after overexpressed miR-142-3p in Ishikawa cells (Fig. 4a). The results revealed that CTNNB1 and AXIN-2 were significantly downregulated (Fig. 4c, d), while APC showed no difference (Fig. 4b), consistent with the expression in human leiomyoma samples. Furthermore, the inhibition rate of cell proliferation was lower (Fig. 5).

\section{Discussion}

Canonical Wnt/ $\beta$-catenin signalling pathway has been reported to be involved in UL pathobiology. Selective overexpression of constitutively activated $\beta$-catenin in embryonic uterine mesenchyme and in the uterus of adult mice leads to growth of leiomyoma-like tumours, while selective deletion of $\beta$-catenin in embryonic uterine mesenchyme significantly reduces uterine size and replaces normal myometrium smooth muscle cells with adipocytes.[31] More recently, Ono and colleagues demonstrated that Wnt/ $\beta$ catenin signalling is involved in proliferation of leiomyoma stem cells (representing $1 \%$ of tumour cells) through Wnt paracrine behaviour. The co-treatment of oestrogen and progesterone could induce expression of Wnt11 and Wnt16 in mature leiomyoma cells. Sequentially, through paracrine effects, Wnt11 and Wnt16 bind to leiomyoma stem cell-surface FZD family receptors (FZD1 and FZD7), leading to activation and nuclear translocation of $\beta$-catenin in leiomyoma stem cells with subsequent AXIN2 transcription and stem cell proliferation (Fig. 6). Interestingly, this study validated that AXIN2 transcription was constitutively activate in mature leiomyoma cells, which was not dependent on Wnt secretion. Based on our results, we found that $\beta$-catenin signalling was upregulated in UL, and at a notable higher level in $M L$ vs. MML than SL vs. MSL. Further, miR-142-3p, the validated negative regulator of $\beta$-catenin, was found negatively correlated to $\beta$-catenin expression. Moreover, APC, another potential target gene of miR$142-3 p$, showed no difference in our results, thus was not regulated by miR-142-3p in leiomyomas and myometrium. However, APC as a member of the $\beta$-catenin destruction complex might not be involved in $\beta$ catenin activation in UL pathobiology. Taken together with previous studies, we propose that $\beta$-catenin is initially expressed at high transcriptional level in both SL and ML. However, in SL, the highly expressed $\beta$ catenin transcripts are silenced partially by upregulated miR-142-3p, as the biological function of miRNAs is post-transcriptional negative regulation of target genes. Conversely, the lower level of miR-142-3p in ML than $M M L$ enhances $\beta$-catenin upregulation in $M L$, resulting in upregulation of $\beta$-catenin in $M L v s . M M L$ at a notable higher level than SL vs. MSL. Further, MED12 gene, which is reported to regulate canonical Wnt signalling through direct binding to $\beta$-catenin,[36] is altered in about $70 \%$ of leiomyomas[18] and is correlated to higher possibility of ML.[37] However, it is unknown whether the mutated MED12 in leiomyoma cells leads to $\beta$-catenin signalling alternation. However, the difference between MSL and MML 
is hardly explained by MED12 alternation in leiomyomas. In addition, Markowski et al. reported that Wnt4b was expressed at higher level in MED12 altered UL cells,[38] leading to the speculation that MED12 mutation in UL is more likely to be involved in paracrine signalling of stem cell activation. Taken together, evidence suggests that $\beta$-catenin activation in leiomyomas is regulated at least partially by miR$142-3 p$ negatively regulation during post-transcriptional process. Further studies to elucidate the regulatory mechanism of miR-142-3p targeting CTNNB1 and APC are expected in the future.

\section{Conclusion}

After myomectomy, women with $\mathrm{ML}$ suffer greater recurrence probability than SL. In the uterus of $\mathrm{ML}$ patients, it is impossible to thoroughly remove undetected leiomyomas during myomectomy, possibly contributing to recurrence. However, SL rarely spreads into multiple areas during the course of the disease. More interestingly, differential expression of miRNAs (miR142-3p and miR-136-3p) and $\beta$-catenin signalling in the myometrium of $S L$ and $M L$, together with exclusive gene subgroup correlations with $S L$ and $M L$, indicates that $\mathrm{ML}$ is more similar to "myometrial disease" than simple leiomyoma disease. Thus, with the gradually deepening understanding of UL pathobiology, individualised clinical decision of myomectomy or hysterectomy could be guided by evidence of specific disease grading biomarkers, and more importantly, molecular intervention for leiomyoma could become possible.

\section{List Of Abbreviations}

UL: uterine leiomyoma

SL: solitary leiomyoma

ML: multiple leiomyomas

FC: fold-change

MSL: myometrium of solitary leiomyomas

MML: myometrium of multiple leiomyomas

\section{Declarations}

\section{Ethics approval and consent to participate}

Written informed consents were obtained from all patients, and the study protocol was approved by Institutional Review Board of West China Second University Hospital.

\section{Availability of data and material}


The datasets used and/or analysed during the current study are available from the corresponding author on reasonable request.

\section{Consent for publication}

Not applicable.

\section{Competing interests}

The authors declare that they have no competing interests.

\section{Funding}

The study was funded by National Natural Science Foundation of China (Grant Number: 81170592/H0420). No role of funding.

\section{Authors' contributions}

L.X. contributed to the conception and design of the study, sample collection and preparation, interpretation of data, manuscript drafting and final approval. E.Y. contributed to the sample collection and preparation and manuscript drafting. Z.L. contributed to conception of the study and design, manuscript revising and critical discussion. J.G. contributed to figures design and data analysis. N.D., J.F. and J.J. contributed to sample collection and data analysis. T.Y. contributed to experiment guidance. All authors have read and approved the final manuscript.

\section{Acknowledgments}

We acknowledgements the staff of the Key Laboratory of Birth Defects and Related Diseases of Women and Children (Sichuan University), Ministry of Education, Chengdu, People's Republic of China, for the methods instruction of the study.

\section{References}

1. Cardozo ER, Clark AD, Banks NK, Henne MB, Stegmann BJ, Segars JH: The estimated annual cost of uterine leiomyomata in the United States. American journal of obstetrics and gynecology 2012, 206(3).

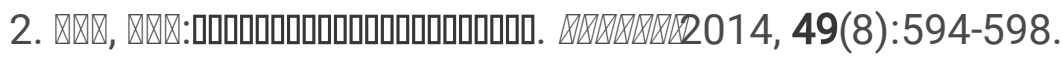

3. Radosa MP, Owsianowski Z, Mothes A, Weisheit A, Vorwergk J, Asskaryar FA, Camara O, Bernardi TS, Runnebaum IB: Long-term risk of fibroid recurrence after laparoscopic myomectomy. European journal of obstetrics, gynecology, and reproductive biology 2014, 180:35-39.

4. Obed JY, Bako B, Usman JD, Moruppa JY, Kadas S: Uterine fibroids: risk of recurrence after myomectomy in a Nigerian population. Archives of gynecology and obstetrics 2011, 283(2):311-315. 
5. Nishiyama S, Saito M, Sato K, Kurishita M, Itasaka T, Shioda K: High recurrence rate of uterine fibroids on transvaginal ultrasound after abdominal myomectomy in Japanese women. Gynecologic and obstetric investigation 2006, 61(3):155-159.

6. Nezhat FR, Roemisch M, Nezhat CH, Seidman DS, Nezhat CR: Recurrence rate after laparoscopic myomectomy. The Journal of the American Association of Gynecologic Laparoscopists 1998, 5(3):237-240.

7. Malone LJ: Myomectomy - Recurrence after Removal of Solitary and Multiple Myomas. Obstetrics and gynecology 1969, 34(2):200-\&.

8. Kim DH, Kim ML, Song T, Kim MK, Yoon BS, Seong SJ: Is myomectomy in women aged 45 years and older an effective option? European Journal of Obstetrics \& Gynecology and Reproductive Biology 2014, 177:57-60.

9. Hanafi M: Predictors of leiomyoma recurrence after myomectomy. Obstetrics and gynecology 2005 , 105(4):877-881.

10. Friedman AJ, Daly M, Juneau-Norcross M, Fine C, Rein MS: Recurrence of myomas after myomectomy in women pretreated with leuprolide acetate depot or placebo. Fertility and sterility 1992, 58(1):205-208.

11. Fedele L, Parazzini F, Luchini L, Mezzopane R, Tozzi L, Villa L: Recurrence of Fibroids after Myomectomy - a Transvaginal Ultrasonographic Study. Human Reproduction 1995, 10(7):17951796.

12. Emanuel MH, Wamsteker K, Hart AA, Metz G, Lammes FB: Long-term results of hysteroscopic myomectomy for abnormal uterine bleeding. Obstetrics and gynecology 1999, 93(5 Pt 1):743-748.

13. Candiani GB, Fedele L, Parazzini F, Villa L: Risk of recurrence after myomectomy. British journal of obstetrics and gynaecology 1991, 98(4):385-389.

14. Stewart EA, Faur AV, Wise LA, Reilly RJ, Harlow BL: Predictors of subsequent surgery for uterine leiomyomata after abdominal myomectomy. Obstetrics and gynecology 2002, 99(3):426-432.

15. Rossetti A, Sizzi O, Soranna L, Cucinelli F, Mancuso S, Lanzone A: Long-term results of laparoscopic myomectomy: recurrence rate in comparison with abdominal myomectomy. Human reproduction (Oxford, England) 2001, 16(4):770-774.

16. Sukur YE, Kankaya D, Ates C, Sertcelik A, Cengiz SD, Aytac R: Clinical and histopathologic predictors of reoperation due to recurrence of leiomyoma after laparotomic myomectomy. International journal of gynaecology and obstetrics: the official organ of the International Federation of Gynaecology and Obstetrics 2015, 129(1):75-78.

17. Mehine M, Kaasinen E, Heinonen HR, Makinen N, Kampjarvi K, Sarvilinna N, Aavikko M, Vaharautio A, Pasanen A, Butzow R et al: Integrated data analysis reveals uterine leiomyoma subtypes with distinct driver pathways and biomarkers. Proceedings of the National Academy of Sciences of the United States of America 2016, 113(5):1315-1320.

18. Makinen N, Mehine M, Tolvanen J, Kaasinen E, Li Y, Lehtonen HJ, Gentile M, Yan J, Enge M, Taipale $\mathrm{M}$ et al: MED12, the mediator complex subunit 12 gene, is mutated at high frequency in uterine 
leiomyomas. Science (New York, NY) 2011, 334(6053):252-255.

19. Bol S, Wanschura S, Thode B, Deichert U, Van de Ven WJ, Bartnitzke S, Bullerdiek J: An endometrial polyp with a rearrangement of HMGI-C underlying a complex cytogenetic rearrangement involving chromosomes 2 and 12. Cancer genetics and cytogenetics 1996, 90(1):88-90.

20. Pakiz M, Potocnik U, But I: Solitary and multiple uterine leiomyomas among Caucasian women: two different disorders? Fertility and sterility 2010, 94(6):2291-2295.

21. Pakiz M, Potocnik U, But I, Mujezinovic F: A CYP17A1 gene polymorphism in association with multiple uterine leimyomas; a meta-analysis. Cancer biomarkers : section A of Disease markers 2010, 8(1):29-34.

22. Bartel DP: MicroRNAs: genomics, biogenesis, mechanism, and function. Cel/ 2004, 116(2):281-297.

23. Wang T, Zhang X, Obijuru L, Laser J, Aris V, Lee P, Mittal K, Soteropoulos P, Wei JJ: A micro-RNA signature associated with race, tumor size, and target gene activity in human uterine leiomyomas. Genes, chromosomes \& cancer 2007, 46(4):336-347.

24. Luo X, Chegini N: The expression and potential regulatory function of microRNAs in the pathogenesis of leiomyoma. Seminars in reproductive medicine 2008, 26(6):500-514.

25. Marsh EE, Lin Z, Yin P, Milad M, Chakravarti D, Bulun SE: Differential expression of microRNA species in human uterine leiomyoma versus normal myometrium. Fertility and sterility 2008, 89(6):17711776.

26. Borahay MA, Al-Hendy A, Kilic GS, Boehning D: Signaling Pathways in Leiomyoma: Understanding Pathobiology and Implications for Therapy. Molecular Medicine 2015, 21:242-256.

27. Moravek MB, Bulun SE: Endocrinology of uterine fibroids: steroid hormones, stem cells, and genetic contribution. Current opinion in obstetrics \& gynecology 2015, 27(4):276-283.

28. Schmittgen TD, Livak KJ: Analyzing real-time PCR data by the comparative C-T method. Nat Protoc 2008, 3(6):1101-1108.

29. Livak KJ, Schmittgen TD: Analysis of relative gene expression data using real-time quantitative PCR and the 2(T)(-Delta Delta C) method. Methods 2001, 25(4):402-408.

30. Carraro G, Shrestha A, Rostkovius J, Contreras A, Chao CM, El Agha E, Mackenzie B, Dilai S, Guidolin D, Taketo MM et al: miR-142-3p balances proliferation and differentiation of mesenchymal cells during lung development. Development 2014, 141(6):1272-1281.

31. Tanwar PS, Lee HJ, Zhang LH, Zukerberg LR, Taketo MM, Rueda BR, Teixeira JM: Constitutive Activation of Beta-Catenin in Uterine Stroma and Smooth Muscle Leads to the Development of Mesenchymal Tumors in Mice. Biology of reproduction 2009, 81(3):545-552.

32. Isobe T, Hisamori S, Hogan DJ, Zabala M, Hendrickson DG, Dalerba P, Cai S, Scheeren F, Kuo AH, Sikandar SS et al: miR-142 regulates the tumorigenicity of human breast cancer stem cells through the canonical WNT signaling pathway. eLife 2014, 3.

33. Hu T, Phiwpan K, Guo J, Zhang W, Guo J, Zhang Z, Zou M, Zhang X, Zhang J, Zhou X: MicroRNA-1423p Negatively Regulates Canonical Wnt Signaling Pathway. PloS one 2016, 11(6):e0158432. 
34. Shrestha A, Carraro G, El Agha E, Mukhametshina R, Chao CM, Rizvanov A, Barreto G, Bellusci S: Generation and Validation of miR-142 Knock Out Mice. PloS one 2015, 10(9).

35. Ono M, Yin P, Navarro A, Moravek MB, Coon JSt, Druschitz SA, Serna VA, Qiang W, Brooks DC, Malpani SS et al: Paracrine activation of WNT/beta-catenin pathway in uterine leiomyoma stem cells promotes tumor growth. Proceedings of the National Academy of Sciences of the United States of America 2013, 110(42):17053-17058.

36. Kim S, Xu X, Hecht A, Boyer TG: Mediator is a transducer of Wnt/beta-catenin signaling. Journal of Biological Chemistry 2006, 281(20):14066-14075.

37. Markowski DN, Helmke BM, Bartnitzke S, Loning T, Bullerdiek J: Uterine fibroids: do we deal with more than one disease? International journal of gynecological pathology : official journal of the International Society of Gynecological Pathologists 2014, 33(6):568-572.

38. Markowski DN, Bartnitzke S, Loning T, Drieschner N, Helmke BM, Bullerdiek J: MED12 mutations in uterine fibroids-their relationship to cytogenetic subgroups. International journal of cancer Journal international du cancer 2012, 131(7):1528-1536.

\section{Tables}

Table 1.1: Basic information of up-regulated miRNAs in 3 pairs of SL group in microarray analysis. 


Up-regulated miRNAs
in 3 pairs of SL vs.
MSL

hsa-miR-142-3p

hsa-miR-146b-5p

hsa-miR-146a-5p

hsa-miR-136-3p

hsa-miR-148a-3p

hsa-miR-409-3p

hsa-miR-379-5p

hsa-miR-136-5p

hsa-miR-181c-5p

hsa-miR-337-3p

hsa-miR-590-5p

hsa-miR-134-5p

hsa-miR-455-3p

hsa-miR-873-5p

hsa-miR-410-3p

hsa-miR-190a-5p

hsa-miR-2681-5p

hsa-miR-876-5p

hsa-miR-374c-5p

hsa-miR-4262

hsa-miR-320e

hsa-miR-4329

hsa-miR-376b-3p

hsa-miR-127-5p

hsa-miR-493-5p

hsa-miR-369-3p

hsa-miR-24-2-5p

hsa-miR-514a-3p

hsa-miR-3142

hsa-miR-181b-5p

hsa-miR-320d

hsa-miR-4518

hsa-miR-378e

hsa-miR-378a-5p

hsa-miR-376a-3p

hsa-miR-378c

hsa-miR-4510

hsa-miR-559
Expression

condition

in ML vs.

MMLs

FDR

Rate for

expression level

and stability

not

dysregulated

0.088152292

down-regulated $\quad 0.059944026$

3

2

down-regulated $\quad 0.114091263$

down-regulated $\quad 0.076432199$

not

dysregulated $\quad 0.086523507 \quad 3$

not

dysregulated $\quad 0.076488334$

down-regulated $\quad 0.043566898$

not

$\begin{array}{llll}\text { dysregulated } & 0.070079172 & 3 & \mathrm{n}\end{array}$

down-regulated $0.055538703 \quad 1 \quad n$

up-regulated $\quad 0.041836652$

$\begin{array}{lll}\text { up-regulated } & 0.04912571 & 1\end{array}$

not

$\begin{array}{llll}\text { dysregulated } & 0.075028211 & 1 & \mathrm{n}\end{array}$

up-regulated $\quad 0.073756991 \quad 2$

up-regulated $\quad 0.090667557 \quad 2$

down-

regulated]

0.131152247

$\mathrm{n}$

fibrogenesis/ endometrial carcinoma

$23741524 ; 25329664 ; 25174797$

Wnt signaling/TGF signaling

$23598417 ; 26498065$

$\mathrm{n}$

Wnt signaling/fibrogenesis

25861021

regulated by oxytocin in pregnant human 25757635

myometrium

up-regulated $0.063495551 \quad 1 \quad n$

$\begin{array}{llll}\text { up-regulated } & 0.082976698 & & \mathrm{n}\end{array}$

up-regulated $\quad 0.087282116 \quad 2 \quad n$

$\begin{array}{llll}\text { up-regulated } & 0.071971095 & 2 & \mathrm{n}\end{array}$

$\begin{array}{llll}\text { up-regulated } & 0.072746943 & 2 & \mathrm{n}\end{array}$

$\begin{array}{llll}\text { up-regulated } & 0.072741496 & 2 & \mathrm{n}\end{array}$

$\begin{array}{llll}\text { up-regulated } & 0.062816523 & 2 & \mathrm{n}\end{array}$

$\begin{array}{llll}\text { up-regulated } & 0.004204048 & 1 & \mathrm{n}\end{array}$

$\begin{array}{llll}\text { up-regulated } & 0.067899071 & 1 & \mathrm{n}\end{array}$

$\begin{array}{llll}\text { up-regulated } & 0.078573238 & 1 & \mathrm{n}\end{array}$

$\begin{array}{llll}\text { up-regulated } & 0.07419817 & 1 & \mathrm{n}\end{array}$

$\begin{array}{llll}\text { up-regulated } & 0.065731692 & 1 & \mathrm{n}\end{array}$

$\begin{array}{llll}\text { up-regulated } & 0.122551745 & 1 & \mathrm{n}\end{array}$

up-regulated $\quad 0.058043324$

up-regulated $\quad 0.075921375$

up-regulated $\quad 0.076288831$

up-regulated $\quad 0.072359645$

up-regulated $\quad 0.088619751$

up-regulated $\quad 0.082843108$

up-regulated $\quad 0.051767842$

up-regulated $\quad 0.07496228$

up-regulated $\quad 0.081183999$

up-regulated $\quad 0.079776491$

etc.

21472990;26673617;26338965

etc.

21472990;26673617;26338965

etc.

24025743

20570858

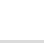

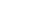

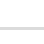

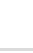

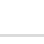

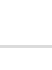

and


Note: FDR, false discovery rate.

Table 1.2: Basic information of down-regulated miRNAs in 3 pairs of SL group in microarray analysis.

\begin{tabular}{|c|c|c|c|c|c|}
\hline $\begin{array}{l}\text { Down-regulated } \\
\text { miRNAs in } 3 \\
\text { pairs of SL vs. } \\
\text { MSL }\end{array}$ & $\begin{array}{l}\text { Expression } \\
\text { condition } \\
\text { in ML vs. } \\
\text { MMLs } \\
\end{array}$ & FDR & $\begin{array}{l}\text { Rate for expression } \\
\text { level and stability }\end{array}$ & $\begin{array}{l}\text { validated function potentially } \\
\text { related to leiomyoma genesis }\end{array}$ & PMID \\
\hline hsa-miR-2116-5p & $\begin{array}{l}\text { not } \\
\text { dysregulated }\end{array}$ & 0.006942901 & 1 & $\mathrm{n}$ & \\
\hline hsa-miR-4434 & up-regulated & 0.0961262 & 1 & $\mathrm{n}$ & \\
\hline hsa-miR-657 & $\begin{array}{l}\text { not } \\
\text { dysregulated }\end{array}$ & 0.099135579 & 1 & nuclear factor kappa B pathway & 23175432 \\
\hline hsa-miR-4455 & $\begin{array}{l}\text { not } \\
\text { dysregulated }\end{array}$ & 0.089060249 & 1 & $\mathrm{n}$ & \\
\hline hsa-miR-371a-5p & up-regulated & 0.345874261 & 1 & $\mathrm{n}$ & \\
\hline hsa-miR-4764-5p & $\begin{array}{l}\text { not } \\
\text { dysregulated }\end{array}$ & 0.124971772 & 1 & $\mathrm{n}$ & \\
\hline hsa-miR-4533 & $\begin{array}{l}\text { down- } \\
\text { regulated }\end{array}$ & 0.043536253 & 1 & $\mathrm{n}$ & \\
\hline hsa-miR-4531 & $\begin{array}{l}\text { down- } \\
\text { regulated }\end{array}$ & 0.094286169 & 1 & $\mathrm{n}$ & \\
\hline hsa-miR-4450 & $\begin{array}{l}\text { down- } \\
\text { regulated }\end{array}$ & 0.086414491 & 1 & $\mathrm{n}$ & \\
\hline hsa-miR-4644 & $\begin{array}{l}\text { down- } \\
\text { regulated }\end{array}$ & 0.103584587 & 2 & $\mathrm{n}$ & \\
\hline hsa-miR-1321 & $\begin{array}{l}\text { down- } \\
\text { regulated }\end{array}$ & 0.10492994 & 1 & $\mathrm{n}$ & \\
\hline hsa-miR-144-3p & $\begin{array}{l}\text { down- } \\
\text { regulated }\end{array}$ & 0.101805887 & & & \\
\hline $\begin{array}{l}\text { ebv-miR-BART18- } \\
3 p\end{array}$ & $\begin{array}{l}\text { down- } \\
\text { regulated }\end{array}$ & 0.211312223 & & & \\
\hline hsa-miR-642b-5p & $\begin{array}{l}\text { down- } \\
\text { regulated }\end{array}$ & 0.130014163 & & & \\
\hline hsa-miR-451a & $\begin{array}{l}\text { down- } \\
\text { regulated }\end{array}$ & 0.132422549 & & & \\
\hline hsa-miR-3189-3p & $\begin{array}{l}\text { down- } \\
\text { regulated }\end{array}$ & 0.286465538 & & & \\
\hline
\end{tabular}

Note: FDR, false discovery rate.

Table 1.3: Basic information of up-regulated miRNAs in 3 pairs of ML group in microarray analysis. 


\begin{tabular}{|c|c|c|c|c|c|}
\hline $\begin{array}{l}\text { Up-regulated } \\
\text { miRNAs } \\
\text { in } 3 \text { pairs of ML } \\
\text { vs. MML }\end{array}$ & $\begin{array}{l}\text { Expression } \\
\text { condition } \\
\text { in SL vs. } \\
\text { MSLs }\end{array}$ & FDR & $\begin{array}{l}\text { Rate for expression } \\
\text { level and stability }\end{array}$ & $\begin{array}{l}\text { validated function potentially related } \\
\text { to leiomyoma genesis }\end{array}$ & PMID \\
\hline hsa-miR-608 & $\begin{array}{l}\text { down- } \\
\text { regulated }\end{array}$ & 0.028423589 & 1 & COL5A1/fibrogenesis & 21609763 \\
\hline hsa-miR-508-5p & $\begin{array}{l}\text { down- } \\
\text { regulated }\end{array}$ & 0.145583719 & 1 & 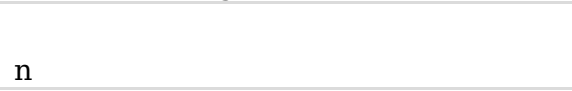 & \\
\hline $\begin{array}{l}\text { hsa-miR-642b- } \\
3 p\end{array}$ & $\begin{array}{l}\text { down- } \\
\text { regulated }\end{array}$ & 0.103626865 & 1 & $\mathrm{n}$ & \\
\hline hsa-miR-92b-5p & $\begin{array}{l}\text { down- } \\
\text { regulated }\end{array}$ & 0.145659557 & 1 & $\mathrm{n}$ & \\
\hline hsa-miR-4669 & $\begin{array}{l}\text { down- } \\
\text { regulated }\end{array}$ & 0.163691464 & 1 & $\mathrm{n}$ & \\
\hline hsa-miR-557 & $\begin{array}{l}\text { down- } \\
\text { regulated }\end{array}$ & 0.112502804 & 1 & $\mathrm{n}$ & \\
\hline $\begin{array}{l}\text { hsa-miR-548a- } \\
5 p\end{array}$ & $\begin{array}{l}\text { down- } \\
\text { regulated }\end{array}$ & 0.191341668 & 1 & $\mathrm{n}$ & \\
\hline hsa-miR-552-3p & $\begin{array}{l}\text { down- } \\
\text { regulated }\end{array}$ & 0.152821825 & 1 & $\mathrm{n}$ & \\
\hline hsv2-miR-H5 & $\begin{array}{l}\text { not } \\
\text { dysregulated }\end{array}$ & 0.196687338 & 1 & $\mathrm{n}$ & \\
\hline hsa-miR-299-3p & up-regulated & 0.134473336 & 1 & Androgen receptor & 21343391 \\
\hline hsa-miR-612 & up-regulated & 0.121511185 & 1 & $\mathrm{n}$ & \\
\hline hsa-miR-625-5p & $\begin{array}{l}\text { not } \\
\text { dysregulated }\end{array}$ & 0.233885171 & 1 & $\mathrm{n}$ & \\
\hline hsa-miR-1264 & up-regulated & 0.145735445 & 2 & $\mathrm{n}$ & \\
\hline $\begin{array}{l}\text { hsa-miR-450a- } \\
5 p\end{array}$ & up-regulated & 0.126128494 & 1 & $\mathrm{n}$ & \\
\hline hsa-miR-345-5p & up-regulated & 0.140784913 & 1 & $\mathrm{n}$ & \\
\hline $\begin{array}{l}\text { hsa-miR-4664- } \\
5 p\end{array}$ & up-regulated & & & & \\
\hline hsa-miR-378g & up-regulated & & & & \\
\hline
\end{tabular}

Note: FDR, false discovery rate.

Table 1.4: Basic information of down-regulated miRNAs in 3 pairs of ML group in microarray analysis.

\begin{tabular}{|c|c|c|c|c|c|}
\hline $\begin{array}{l}\text { Down-regulated } \\
\text { miRNAs } \\
\text { in } 3 \text { pairs of ML vs. } \\
\text { MML }\end{array}$ & $\begin{array}{l}\text { Expression } \\
\text { condition } \\
\text { in SL vs. MSLs }\end{array}$ & FDR & $\begin{array}{l}\text { Rate for expression level } \\
\text { and stability }\end{array}$ & $\begin{array}{l}\text { Validated function } \\
\text { potentially related to } \\
\text { leiomyoma genesis }\end{array}$ & PMID \\
\hline hsa-miR-216a-5p & $\begin{array}{l}\text { not } \\
\text { dysregulated }\end{array}$ & 0.092393532 & 1 & $\begin{array}{l}\text { Hypoxia Inducible Factor } \\
\text { (HIF) } 1 \alpha\end{array}$ & 24927770 \\
\hline hsa-miR-4800-3p & down-regulated & 0.183503741 & 3 & $\mathrm{n}$ & \\
\hline ebv-miR-BART18-3p & down-regulated & 0.116887837 & & $\mathrm{n}$ & \\
\hline hsa-miR-144-3p & down-regulated & 0.128769452 & & $\mathrm{n}$ & \\
\hline
\end{tabular}

Note: FDR, false discovery rate.

\section{Figures}




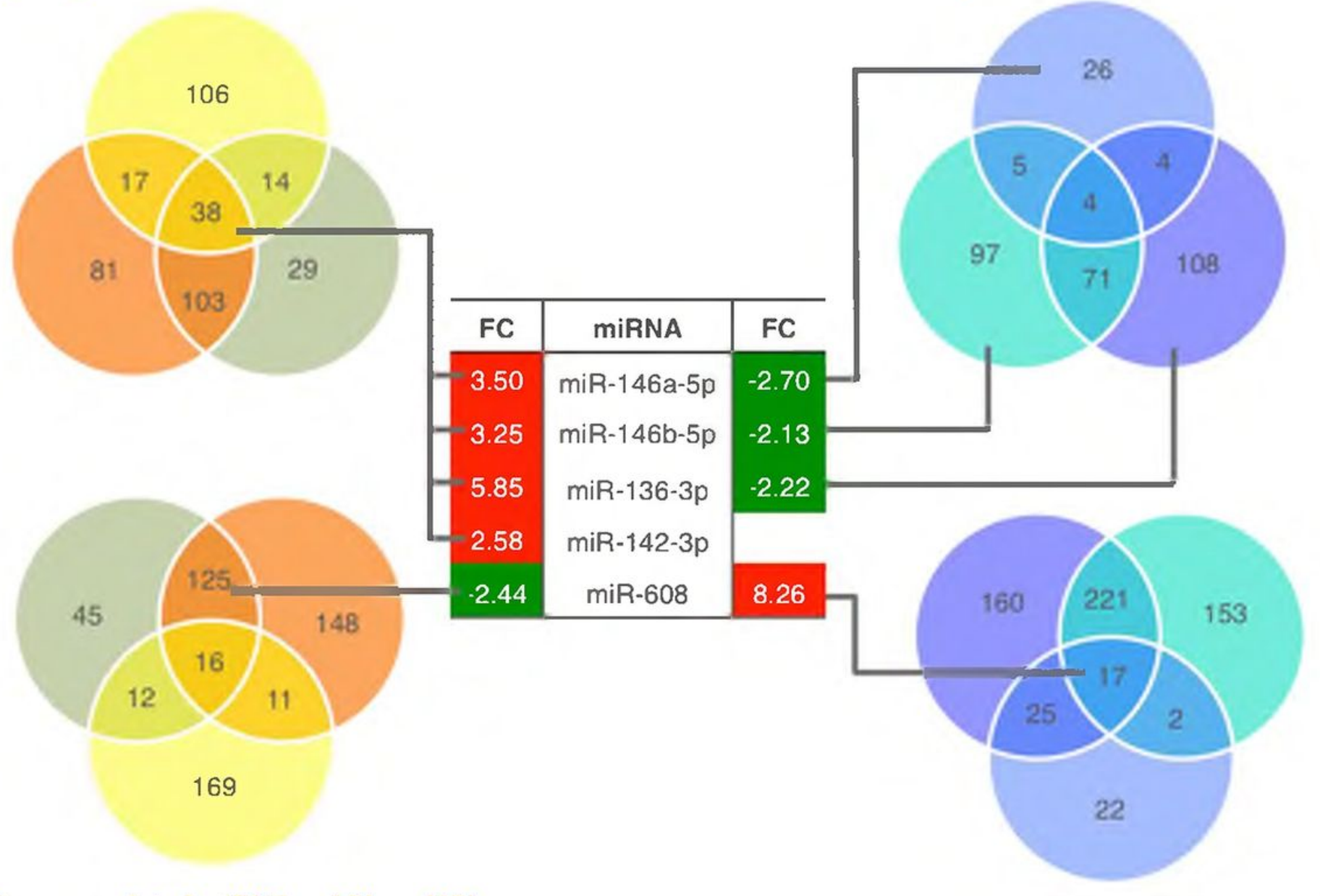

Down-regulated miRNAs of SL vs MSL

Up-regulated miRNAs of ML vs MML

\section{Figure 1}

Potentially dysregulated miRNAs between SL and ML in microarray analysis. SL: solitary leiomyoma, ML: multiple leiomyoma. 
a.

FC of 5 miRNAs in SL vs. MSL and ML vs. MMLs

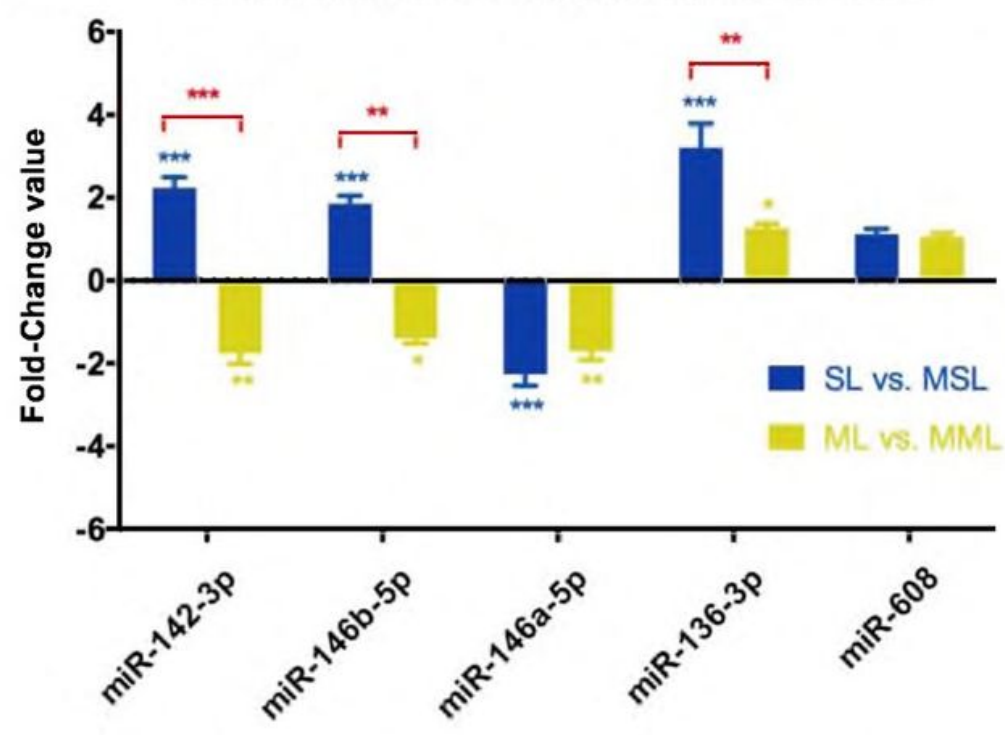

b.

MiR-142-3p

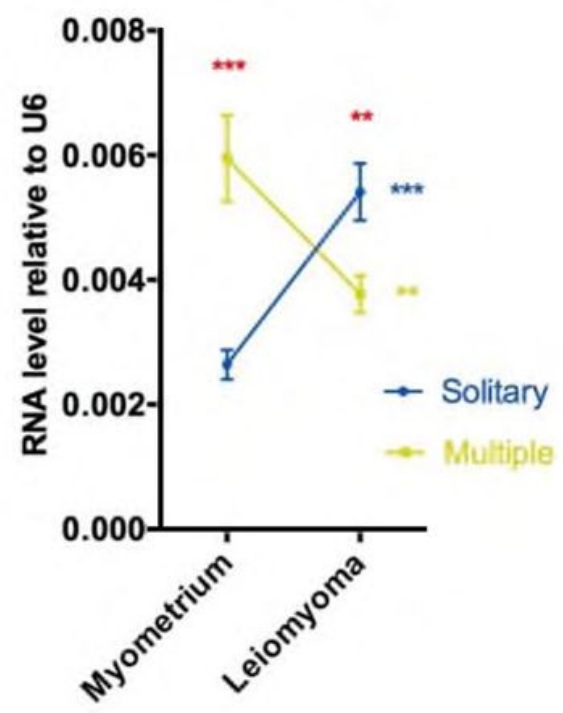

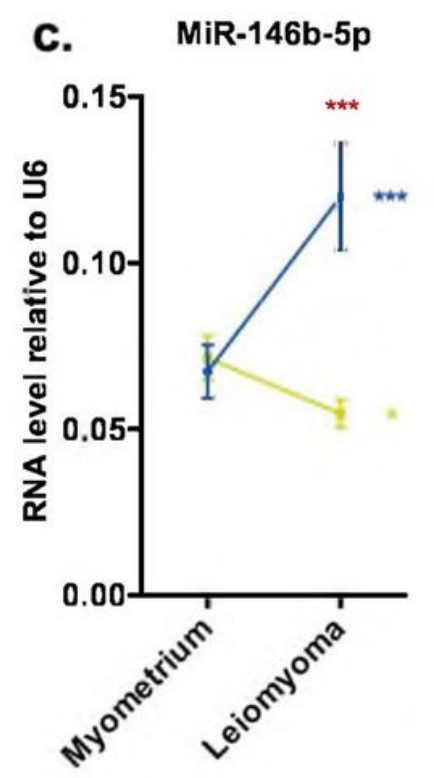

d. MiR-146a-5p
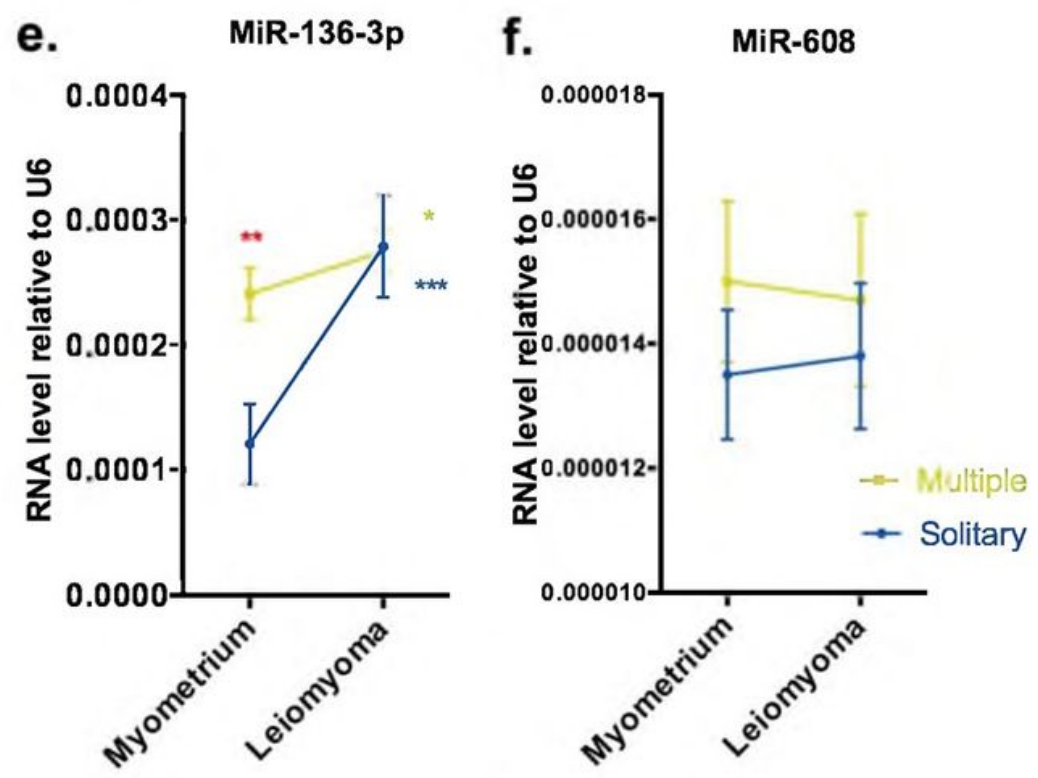

Figure 2

Dysregulated miRNAs between SL and ML in qRT-PCR validation. a, Expressions of 5 miRNAs in 13 pairs of SL and 19 pairs of ML samples; FC: Fold-change value = mean \pm standard error, $2-\Delta \Delta$ Ct methods.

b,c,d,e,f: The relative expressions of miR-142-3p, miR-146b-5p, miR-146a-5p, miR-136-3p and miR-608 in

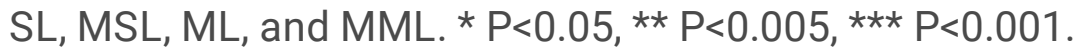


a.

\begin{tabular}{|c|c|}
\hline $\begin{array}{l}\text { APC 3' UTR } \\
\text { miR-142-3p }\end{array}$ & 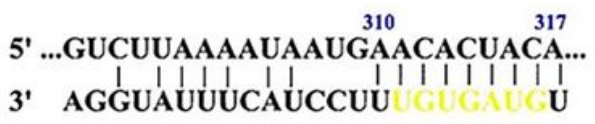 \\
\hline & 406 \\
\hline $\begin{array}{l}\text { CTNNB1 3' UTR } \\
\text { miR-142-3p }\end{array}$ & 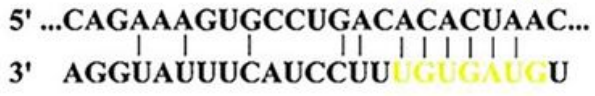 \\
\hline $\begin{array}{l}\text { CTNNB1 3' UTR } \\
\text { miR-142-3p }\end{array}$ & 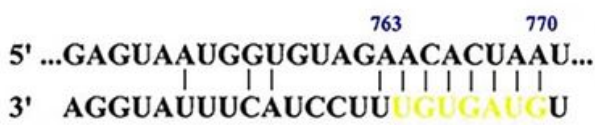 \\
\hline
\end{tabular}

b.

FC of 3 Gene transcripts in SL vs. MSL and ML vs. MML

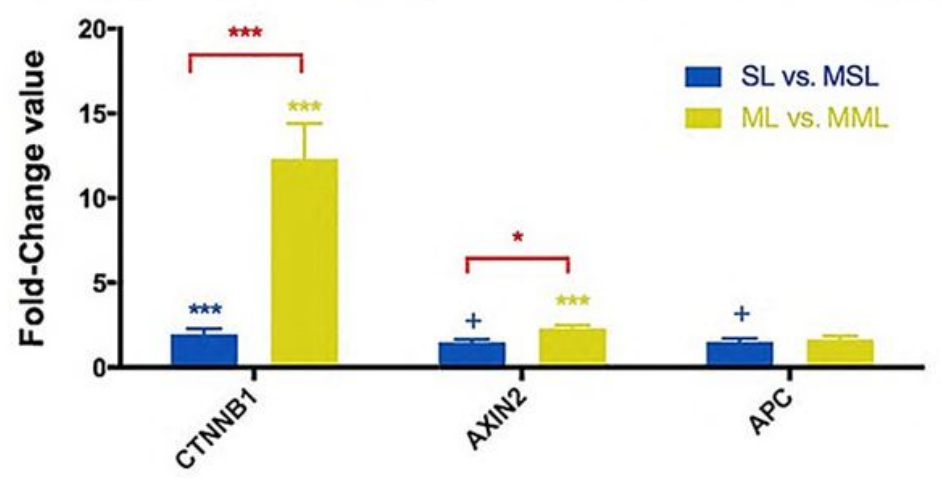

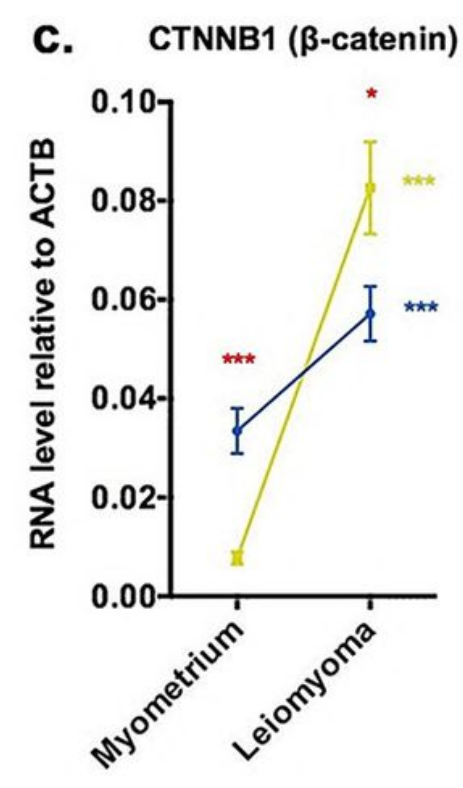
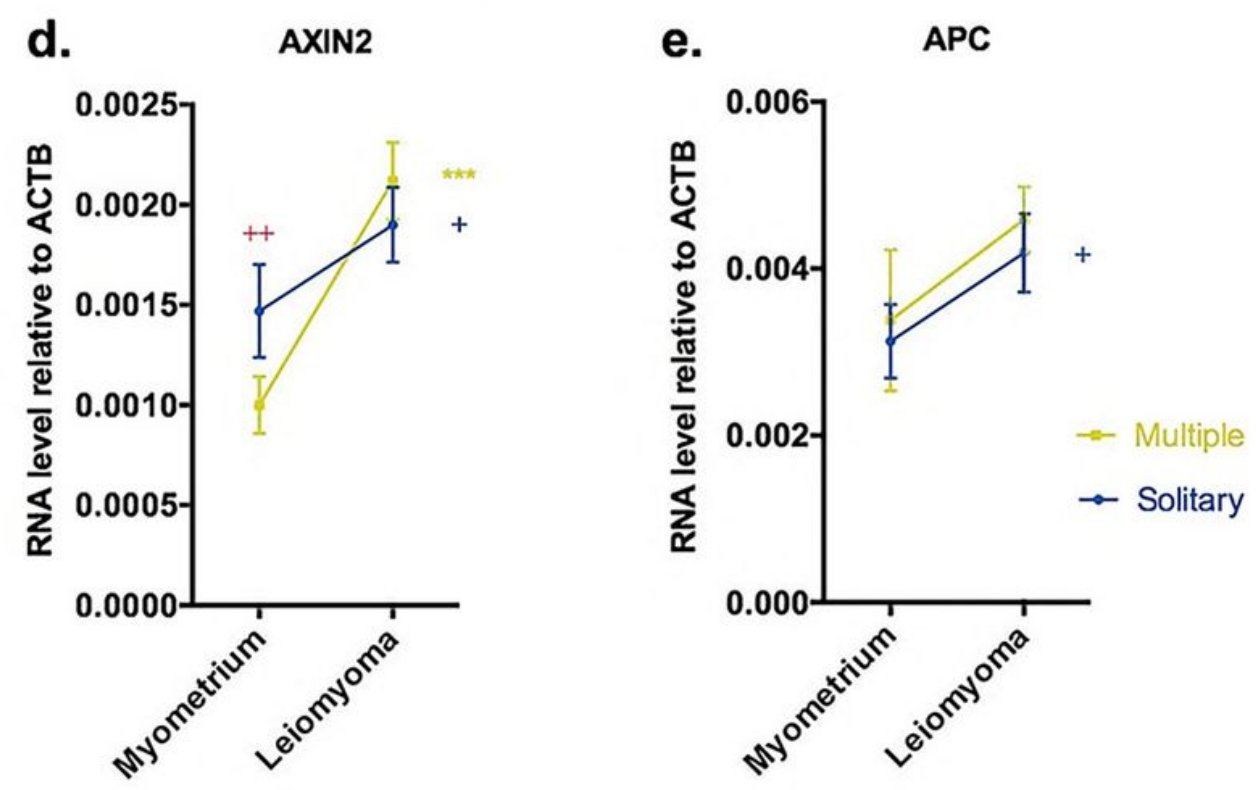

Figure 3

Target genes of miR-142-3p involved in $\beta$-catenin signaling between paired SL and paired ML samples. a. The binding sites between miR-142-3p and its target genes validated by dual-luciferase reporter assay (seed region of miR-142-3p showed in yellow). b. Regulation profile of 3 mRNAs in $\beta$-catenin signaling (CTNNB1 ( $\beta$-catenin) and APC as gene targets of miR-142-3p, AXIN2 as gene targets of $\beta$-catenin signaling) in 10 pairs of $S L$ and 10 pairs of ML samples. CTNNB1: FCSL vs. MSL $=1.952 \pm 0.333, F C M L$ vs. $\mathrm{MML}=12.327 \pm 2.077 ; \mathrm{AXIN2}$ : FCSL vs. $\mathrm{MSL}=1.497 \pm 0.161, \mathrm{FCML}$ vs. $\mathrm{MML}=2.303 \pm 0.188 ; \mathrm{APC}$ : not significant; (Fold-change value $(F C)=$ mean \pm standard error, $2-\Delta \Delta$ Ct methods). $c$, d, e: Expressions of 3 mRNAs in $S L, M S L, M L, M M L . ~ * P<0.05, * \star P<0.005, * \star * ~ P<0.001,+P<0.1,++P<0.11$. 

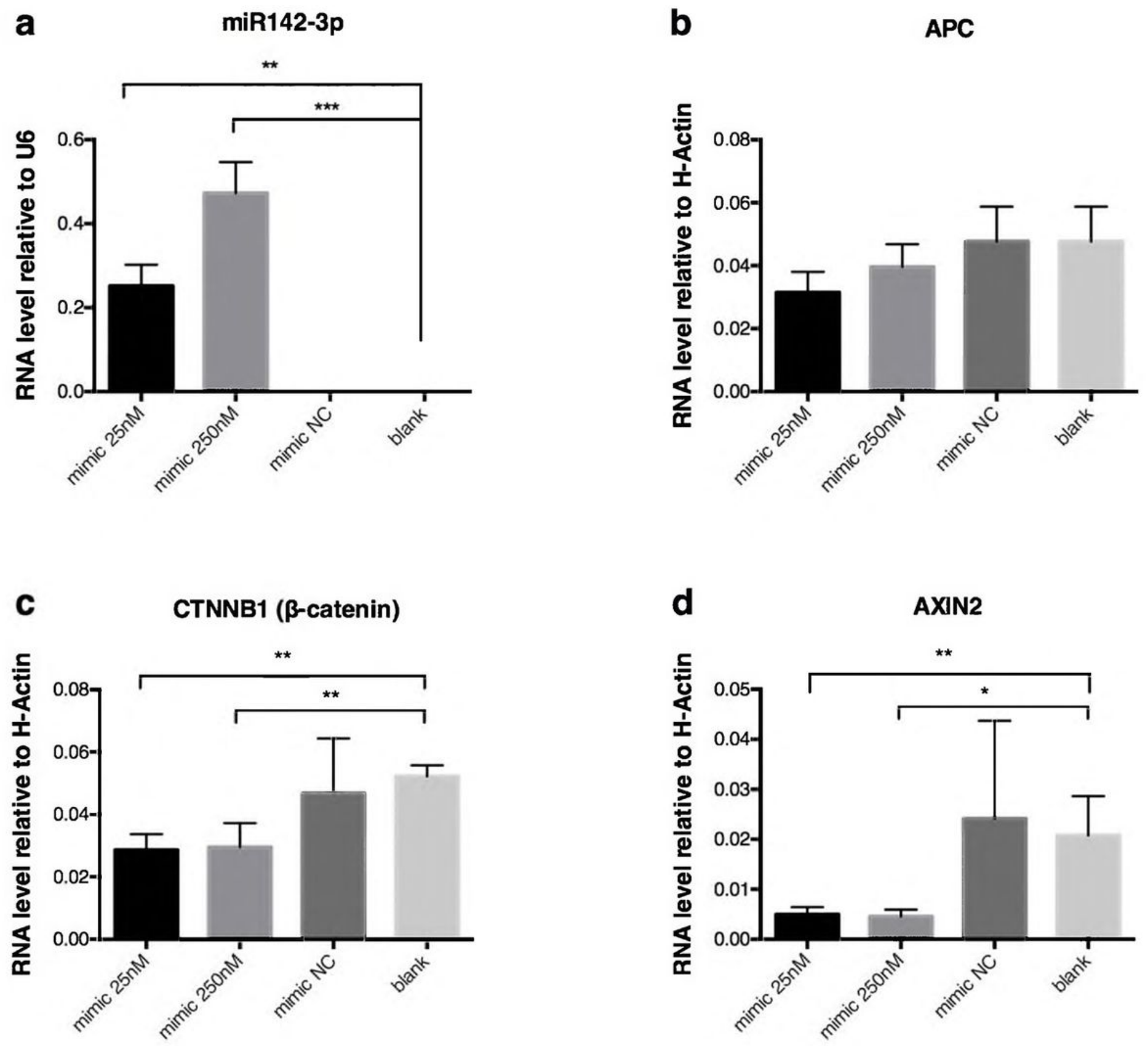

Figure 4

Over-expression of miR-142-3p resulted in CTNNB1( $\beta$-catenin) and $\beta$-catenin signaling down-regulation in vitro. Transfection of miR-142-3p mimics ( $25 \mathrm{nM}$ or $250 \mathrm{nM})$ and its negative control (NC) was carried out in Ishikawa cells, then $\beta$-catenin signaling was activated by treating with $30 \mathrm{mM} \mathrm{LiCl}$, and the transfection effects of miR-142-3p mimics and $\beta$-catenin signaling expression were examined by qRT-PCR. a, MiR-142$3 p$ was validated to be over-expressed after mimic transcription. b, APC mRNA level had no significant differences after over-expression of miR-142-3p. c, CTNNB1 mRNA level was significantly lower after over-expression of miR-142-3p. d, AXIN-2 mRNA level, the down-stream gene of $\beta$-catenin signaling, was

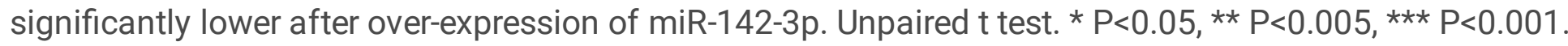




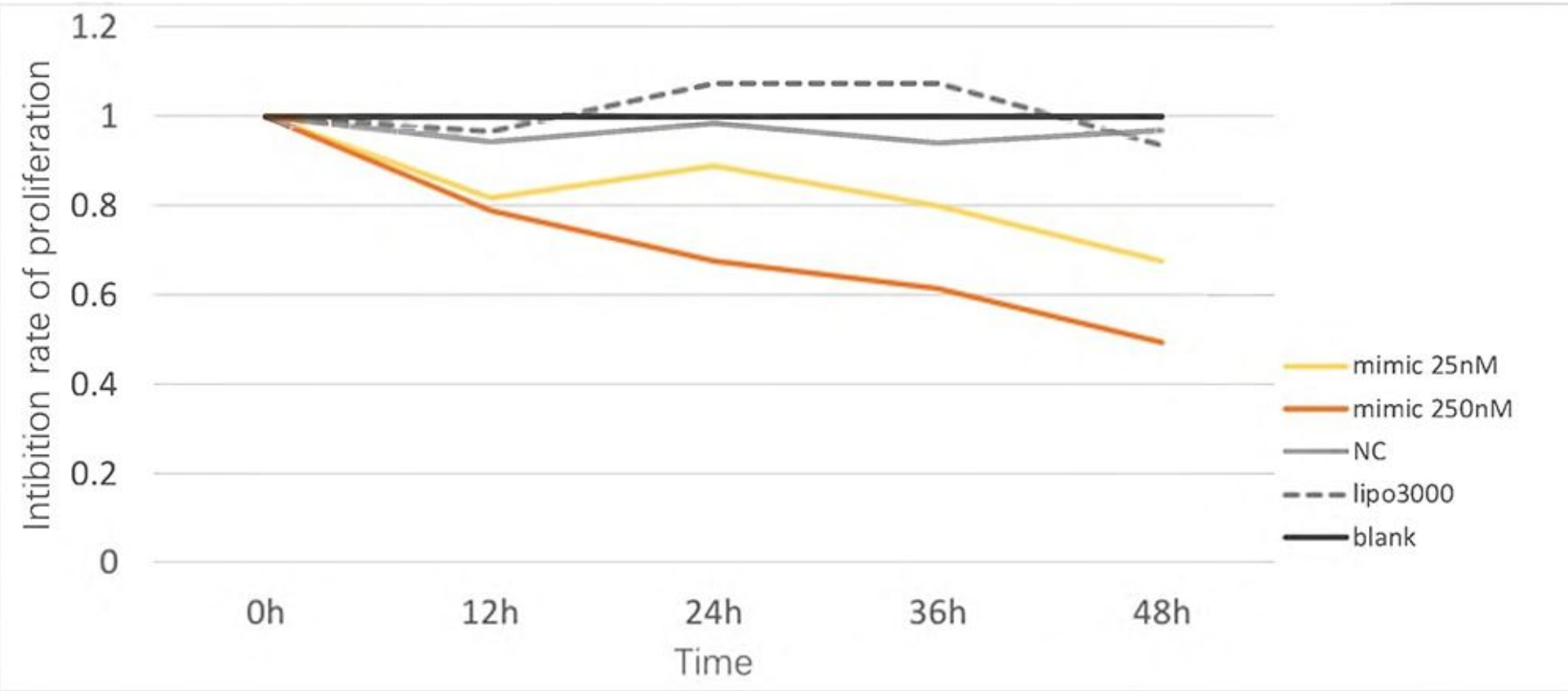

\section{Figure 5}

MiR-142-3p over-expression resulted in inhibition of cell proliferation in vitro. The inhibiton rate of cell proliferation was measured by at $12 \mathrm{~h}, 24 \mathrm{~h}, 36 \mathrm{~h}$ and $48 \mathrm{~h}$ after transfection of miR-142-3p mimics. 


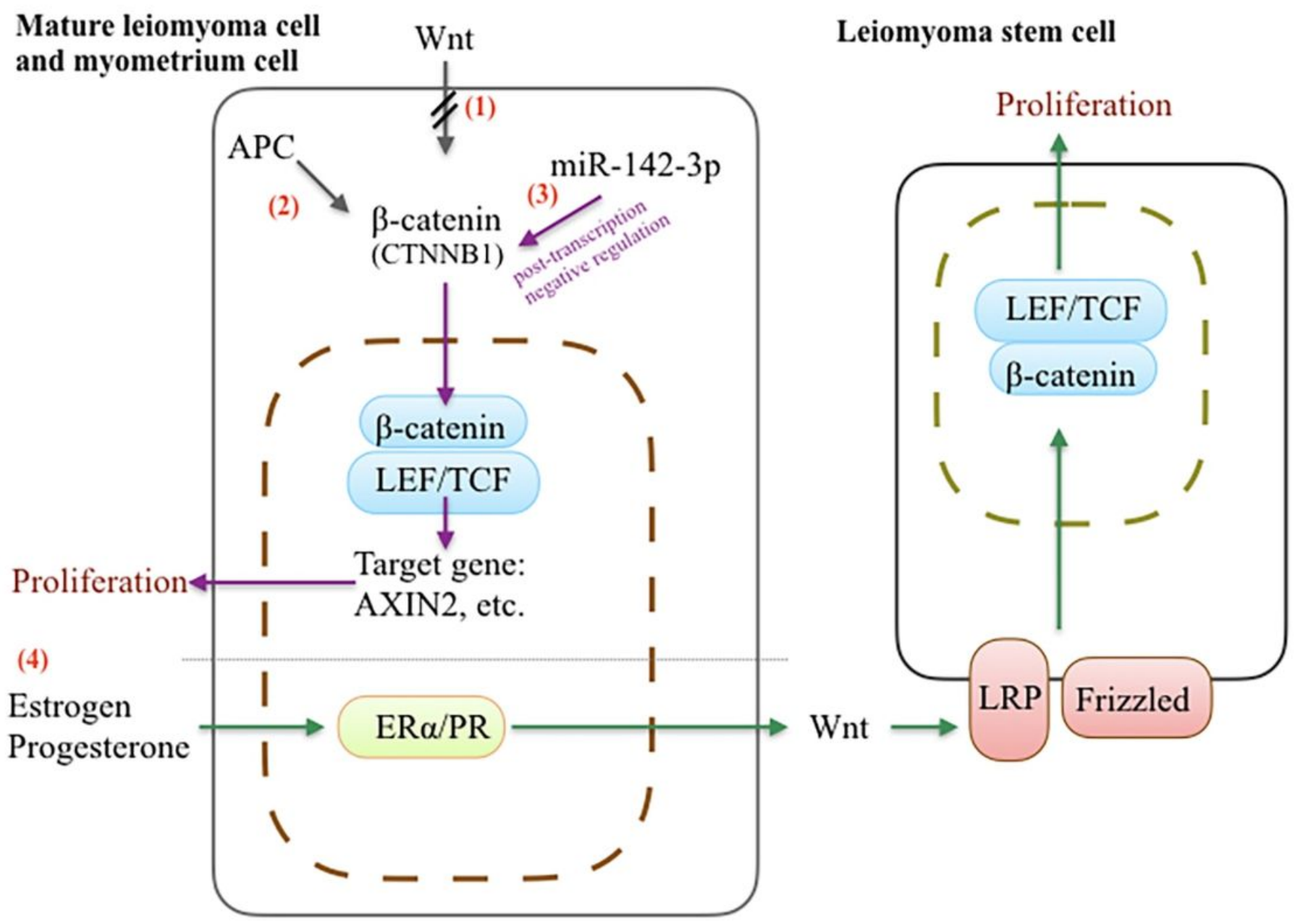

Figure 6

Wnt/ $\beta$-catenin signaling in UL pathogenesis: (1) $\beta$-catenin activity is independent of Wnt expression in mature leiomyoma cells and myometrial cells, demonstrated by Ono and colleagues. (2) APC, a critical member of $\beta$-catenin destruction complex and potential targets of miR142-3p, showed no difference in any comparison, thus it could be told that APC was not targeted by miR-142-3p and was not involved in $\beta$ catenin activation in UL pathobiology. (3) Potential post-transcriptional negative regulation by miR-142$3 p$ directly targeting $\beta$-catenin. (4) Wnt/ $\beta$-catenin signaling is involved in proliferation of leiomyoma stem cells in a Wnt paracrine behavior, raised and demonstrated by Ono and colleagues.

\section{Supplementary Files}

This is a list of supplementary files associated with this preprint. Click to download.

- Supplementaryfile2.docx

- Supplementaryfile1.docx 